\title{
Gene expression and metabolic response of bovine oviduct epithelial cells to the early embryo
}

\author{
Meriem Hamdi ${ }^{1}$, María J Sánchez-Calabuig',2, Beatriz Rodríguez-Alonso ${ }^{1,2,3,4}$, \\ Sandra Bagés Arnal1,2,3,4, Kalliopi Roussi³, Roger Sturmey³, Alfonso Gutiérrez-Adán¹, \\ Patrick Lonergan ${ }^{4}$ and Dimitrios Rizos ${ }^{1}$ \\ ${ }^{1}$ Department of Animal Reproduction, National Institute for Agricultural and Food Research and Technology (INIA), \\ Madrid, Spain, ${ }^{2}$ Department of Animal Medicine and Surgery, Faculty of Veterinary, University Complutense of \\ Madrid (UCM), Madrid, Spain, ${ }^{3}$ Center for Cardiovascular and Metabolic Research, Hull York Medical School, \\ University of Hull, Hull, UK and ${ }^{4}$ School of Agriculture and Food Science, University College Dublin, Belfield, \\ Dublin, Ireland \\ Correspondence should be addressed to D Rizos; Email: drizos@inia.es
}

\begin{abstract}
During its journey through the oviduct, the bovine embryo may induce transcriptomic and metabolic responses, via direct or indirect contact, from bovine oviduct epithelial cells (BOECs). An in vitro model using polyester mesh was established, allowing the study of the local contact during $48 \mathrm{~h}$ between a BOEC monolayer and early embryos (2- or 8-cell stage) or their respective conditioned media (CM). The transcriptomic response of BOEC to early embryos was assessed by analyzing the transcript abundance of SMAD6, TDGF1, ROCK1, ROCK2, SOCS3, PRELP and AGR3 selected from previous in vivo studies and GPX4, NFE2L2, SCN9A, EPSTI1 and IGFBP3 selected from in vitro studies. Moreover, metabolic analyses were performed on the media obtained from the co-culture. Results revealed that presence of early embryos or their CM altered the BOEC expression of NFE2L2, GPX4, SMAD6, IGFBP3, ROCK2 and $S C N 9 A$. However, the response of BOEC to two-cell embryos or their CM was different from that observed to eight-cell embryos or their CM. Analysis of energy substrates and amino acids revealed that BOEC metabolism was not affected by the presence of early embryos or by their CM. Interestingly, embryo metabolism before embryo genome activation (EGA) seems to be independent of exogenous sources of energy. In conclusion, this study confirms that early embryos affect BOEC transcriptome and BOEC response was embryo stage specific. Moreover, embryo affects BOEC via a direct contact or via its secretions. However transcriptomic response of $\mathrm{BOEC}$ to the embryo did not manifest as an observable metabolic response.

Reproduction (2019) 158 85-94
\end{abstract}

\section{Introduction}

During its 4-day journey through the oviduct (Hackett et al. 1993), the bovine embryo undergoes important morphological and transcriptional events such as the first mitotic cell divisions, the timing of which is reflective of developmental competence (Lonergan et al. 1999) and embryonic genome activation (EGA) involving a switch from dependence on transcripts stored in the oocyte to de novo transcription (Memili \& First 2000). There is convincing evidence demonstrating a positive influence of the oviduct on embryo development in terms of embryo cryotolerance, gene expression and developmental competence (Enright et al. 2000, Lazzari et al. 2002, Rizos et al. 2002, Lonergan et al. 2003). However, the embryo effect on the oviduct is less studied. In mice, the presence of embryos in the oviduct increased the expression of specific genes such as thymosin beta-4, ribosomal protein L41 and nonmuscle myosin light chain 3 (Lee et al. 2002). In pigs, Almiñana et al. (2012) reported that the presence of embryos reduced the expression of genes related with immune function. Also, transforming growth factor-alpha, transforming growth factor-beta-binding protein 2 and atrial natriuretic factor receptor-like were upregulated in the presence of four-cell porcine embryos (Chang et al. 2000).

It is likely that the effect of any putative embryoderived signals on the cells of the oviduct would be magnified in litter-bearing species due to the presence of multiple embryos in the oviduct. That notion is supported by a previous study from our group in cattle, a mono-ovulatory species, which failed to detect a transcriptomic response of the oviduct to the presence of a single embryo, while a response was observed after the transfer of multiple embryos (Maillo et al. 2015). In the horse, the presence of a single embryo altered the oviduct transcriptome (Smits et al. 2016), when epithelial cells were collected locally from the ampullary-isthmic 
junction. Combined, these findings suggest that the presence of a single embryo in the oviduct may induce a very local effect on oviduct transcriptome which is difficult to detect. Furthermore, in vivo studies remain challenging, due to the relative inaccessibility of the oviduct. BOECs have been cultured in vitro in many systems, as monolayers, in perfusion chambers, in suspension, in polarized or in 3D systems (reviewed by Maillo et al. 2016). Recent in vitro culture strategies have mimicked the morphological and functional changes occurring in the oviduct epithelium using an air-liquid interface (Chen et al. 2017, 2018) or using the state-of-the-art oviduct-on-a-chip platform (Ferraz et al. 2018). However, considering the complexity of studies aiming to understand the regulatory mechanisms controlling embryo-maternal communication, the simple BOEC in vitro, cultured as a monolayer might provide a good starting point to study embryo signals. For instance, Schmaltz-Panneau et al. (2014) identified differentially expressed genes related to the immune system and interferon signaling by co-culturing early embryos for 8 days on a 13-day-old BOEC monolayer (Schmaltz-Panneau et al. 2014). Also, in a recent study carried out by our group using the BOEC monolayer model, we reported that bovine embryo-oviduct interaction in vitro reveals an early cross-talk mediated by bone morphogenetic protein (BMP) signaling (García et al. 2017).

In order to test the hypothesis that the early embryo induces transcriptional and metabolic changes in BOEC, we established an in vitro co-culture system allowing both local and temporal contact between early bovine embryos and oviduct isthmus epithelial cells, where development occurs in vivo. The objectives were (i) to assess the gene expression response of $\mathrm{BOEC}$ to early embryos and to test whether it is due to a contact-dependent signal or the result of BOEC interaction with embryo secretions and (ii) to examine the metabolic changes of BOEC in the presence or absence of early embryos .

\section{Materials and methods}

\section{Chemicals}

All reagents were purchased from Sigma Chemical Química S.A Company unless otherwise stated.

\section{Bovine oviduct epithelial cell isolation and in vitro culture}

Bovine oviducts at the early luteal phase (corresponding to days 3-5 of the estrous cycle) were obtained from slaughtered heifers and selected based on ovarian morphology, according to Ireland et al. (1980). Oviduct epithelial cell isolation was performed as described previously (García et al. 2017). Cells were cultured at a final concentration of $2 \times 10^{6} \mathrm{cells} / \mathrm{mL}$ with TCM 199 supplemented with $10 \%$ fetal calf serum (FCS), $2.5 \%$ gentamycin and $1 \%$ amphotericin, in four-well plates at $38.5^{\circ} \mathrm{C}$

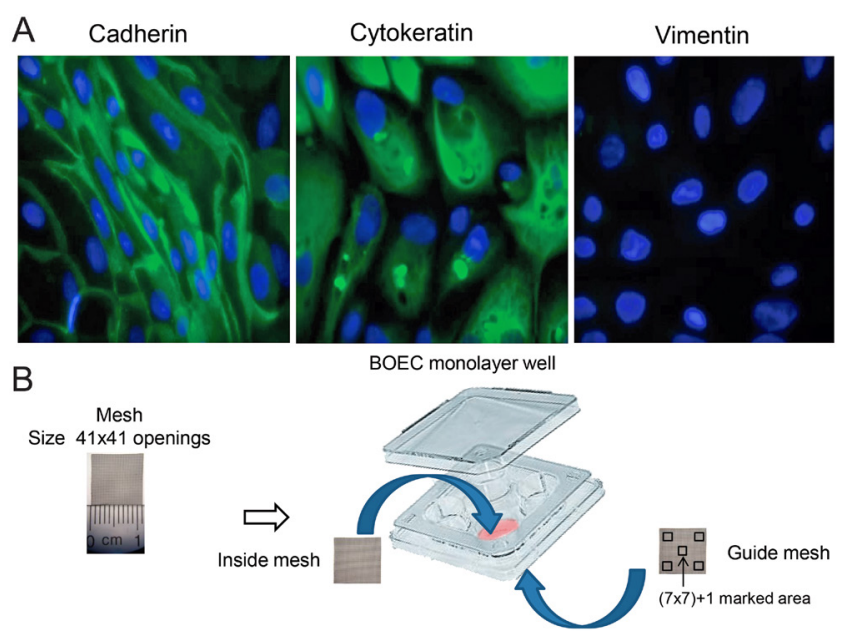

Figure 1 (A) Immunofluorescence analysis of BOEC monolayers showing positive staining for the epithelial markers, cadherin and cytokeratin and negative staining for the fibroblast marker, vimentin. Cell nuclei were counterstained with Hoechst (blue). (B) Representative image of the polyester meshes employed to establish a direct and indirect contact area between the embryos and the BOEC monolayer. A guide mesh of $41 \times 41$ openings, covering an area of $121 \mathrm{~mm}^{2}$, containing delimited marked areas of 50 openings $((7 \times 7)+1)$ was placed outside underneath each well of a four-well dish and was used as a guide to localize the co-culture area. Another mesh square of the same size, fitting exactly into the well, was introduced in a way that the external and internal meshes overlapped during the co-culture.

in an atmosphere of $5 \% \mathrm{CO}_{2}, 20 \% \mathrm{O}_{2}$ and saturated humidity until confluence (6-7 days). Half of the media was renewed every $48 \mathrm{~h}$. Twenty-four hours before starting the co-culture with embryos or their $\mathrm{CM}$, the cell culture media was replaced with Synthetic Oviduct Fluid supplemented with amino acids (SOFaa) $+5 \%$ FCS (see 'Experimental design' section for more details and Fig. 2).

\section{Immunocytochemistry}

The epithelial nature of the cultured cells was confirmed by immunocytochemical analysis using antibodies anti-bovinepancadherin (C1821), anti-bovine-pancytokeratin (C2931) and anti-bovine-vimentin (V2258), as previously described (Lopera-Vásquez et al. 2016) (Fig. 1A).

\section{In vitro production of embryos and their CM}

Immature cumulus oocyte complexes recovered by aspirating follicles (2-8 mm in diameter) from ovaries of heifers slaughtered at a local abattoir were submitted to in vitro maturation and fertilization, as described previously (García et al. 2017). Approximately $18-22 \mathrm{~h}$ after insemination, presumptive zygotes were completely denuded of cumulus cells by vortexing and groups of 50 were initially cultured in $500 \mu \mathrm{L}$ of SOFaa supplemented with $5 \%$ of FCS in a four-well dish under an atmosphere of $5 \% \mathrm{CO}_{2}, 5 \% \mathrm{O}_{2}$ and $90 \% \mathrm{~N}_{2}$ at $38.5^{\circ} \mathrm{C}$. Embryos at the two- and eight-cell stage were selected at 31 and $52 \mathrm{~h}$ post insemination (hpi), respectively, and then randomly cultured either in groups of 50 for $48 \mathrm{~h}$ to produce embryo CM or co-culture with BOEC (see Experimental design, Fig. 2). 


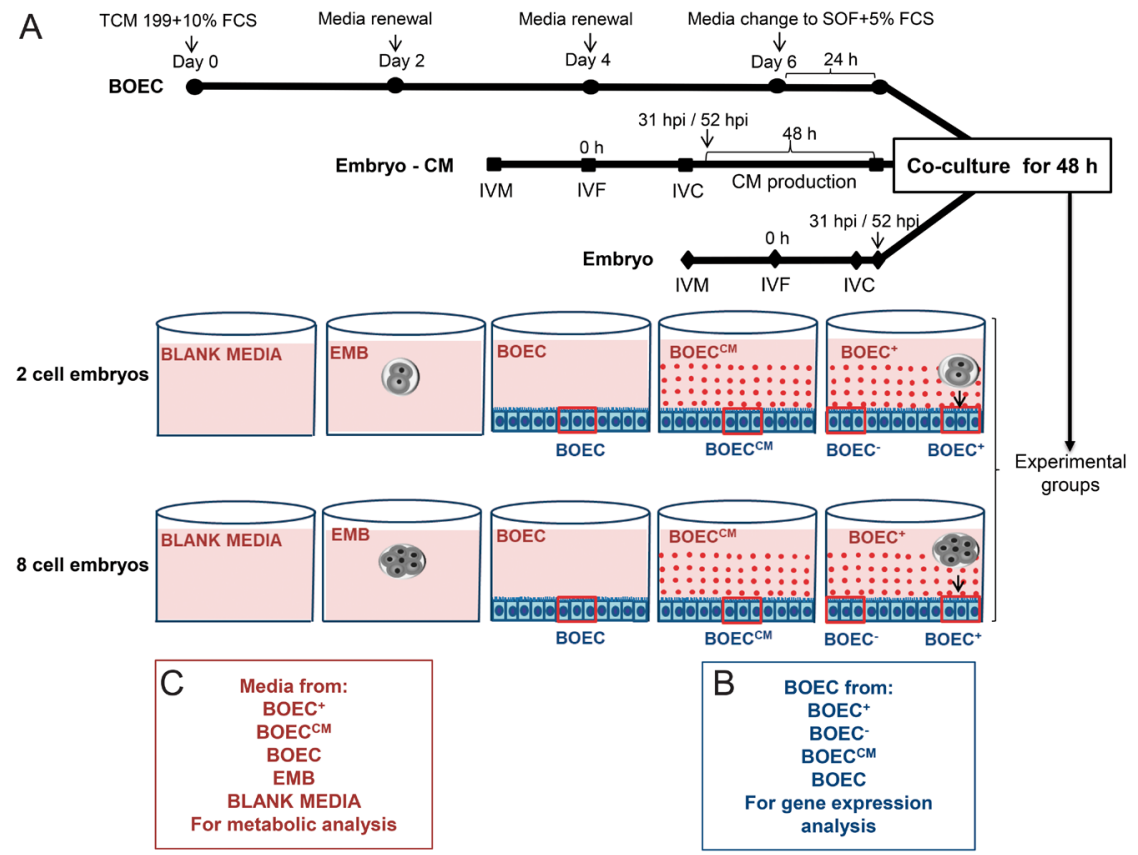

Figure 2 Experimental design. (A) Replicates of BOEC $(n=4)$, embryo CM $(n=4)$ and embryo $(n=4)$ production were carried out in a synchronized way. BOEC were cultured until confluence for 6 days. Half of the media was renewed every $48 \mathrm{~h}$, and $24 \mathrm{~h}$ before starting the co-culture, it was replaced with SOFaa $+5 \%$ FCS. Embryos at the two- and eight-cell stages were generated by IVF $(0 \mathrm{~h})$ and selected at 31 or $52 \mathrm{~h}$ post insemination (hpi) respectively to be cultured during $48 \mathrm{~h}$ to either generate fresh $\mathrm{CM}$ or co-cultured with BOEC. The following experimental groups were established: (1) BOEC directly beneath to 50 embryos at two- or eight-cell stage $\left(\mathrm{BOEC}^{+}\right)$; (2) BOEC in the same well as two- or eight-cell embryos but not in direct contact (BOEC $\left.{ }^{-}\right)$; (3) BOEC cultured with $\mathrm{CM}$ produced from 50 embryos at two- or eight-cell stage (BOEC ${ }^{\mathrm{CM}}$ ); (4) BOEC cultured without embryos (BOEC); (5) embryos at two- or eight-cell stage cultured alone (EMB) and (6) embryo/BOEC-free media as control (BLANK MEDIA). After $48 \mathrm{~h}$ of co-culture, BOEC were recovered from the marked area from groups 1, 2, 3 and 4 to perform gene expression analysis (B), while the media obtained from groups 1, 3, 4, 5 and 6 were collected to assess metabolic analysis of energy substrate and amino acid composition (C).

\section{Mesh preparation and co-culture condition}

In order to limit the area of contact between the embryos and the BOEC monolayer, a nontoxic woven polyester mesh (Sefar Petex; Sefar, Bury, Lancashire, UK) was used as described previously (García et al. 2017). Grids with size of $41 \times 41$ openings covering an area of $121 \mathrm{~mm}^{2}$, fitting perfectly inside the well of a Nunc 4-well dish, were used. First, a template grid containing delimited marked areas of 50 openings $((7 \times 7)+1)$ was placed outside underneath each well of a four-well dish (Fig. 1B). A second mesh square of the same size was washed once with $70 \%$ ethanol and three times with PBS followed by SOFaa media, and then it was introduced into the well, so that the external and internal meshes overlapped (Fig. 1B). During the co-culture, 50 embryos (at the two- or eight- cell stage) were placed inside the BOEC well, over the central marked area. After $48 \mathrm{~h}$ of co-culture, BOEC were collected from the marked area directly beneath the embryos and as well as from other areas of the well that were not in direct contact with the embryos (Fig. 1B) by mechanical scraping with a micropipette tip and snap frozen in liquid nitrogen and maintained at $-80^{\circ} \mathrm{C}$ until gene expression analysis.

\section{RNA isolation and reverse transcription}

mRNA from each experimental group of BOEC was extracted from four biological replicates using Dynabeads mRNA Direct Extraction Kit (Dynal Biotech, Oslo, Norway), following the manufacturer's instructions with minor modifications as described previously (Bermejo-Alvarez et al. 2008). After 10 min of incubation in lysis buffer with Dynabeads, poly(A) RNA attached to the Dynabeads was extracted with a magnet and washed twice in washing buffer $\mathrm{A}$ and washing buffer $\mathrm{B}$. RNA was eluted with Tris- $\mathrm{HCl}$. Immediately after extraction, the reverse transcription reaction was performed as recommended by the manufacturer (Epicentre Technologies Corp, Madison, WI, USA). Briefly, oligo-dT $(0.2 \mu \mathrm{M})$ and random primers $(0.5 \mu \mathrm{M})$ were added to the RNA and were then heated for $5 \mathrm{~min}$ at $70^{\circ} \mathrm{C}$ to denature the secondary RNA structure. Next, the tubes were incubated at $25^{\circ} \mathrm{C}$ for $10 \mathrm{~min}$ to promote the annealing of random primers. Then, the RNA was reversetranscribed for $60 \mathrm{~min}$ at $37^{\circ} \mathrm{C}$ in a final volume of $40 \mu \mathrm{L}$ containing $0.375 \mathrm{mM}$ dNTPs (Biotools, Madrid, Spain), $6.25 \mathrm{U}$ RNasin RNAse inhibitor (Promega), 10× MMLV-RT buffer with $8 \mathrm{mM}$ dithiothreitol and $5 \mathrm{U}$ MMLV high-performance reverse transcriptase (Epicentre Technologies Corp), followed by incubation at $85^{\circ} \mathrm{C}$ for $5 \mathrm{~min}$ to inactivate the RT enzyme.

\section{Gene expression analysis by quantitative real-time polymerase chain reaction}

The mRNA expression levels of the selected genes were determined by real-time quantitative reverse transcription polymerase chain reaction (RT-qPCR) using specific primers designed with Primer-BLAST software (http://www.ncbi.nlm. nih.gov/tools/primer-blast/) to span exon-exon boundaries when possible (Table 1). Primers were previously validated for adequate primer efficiency and specificity of their PCR 
Table 1 Set of primers used for qRT-PCR assays.

\begin{tabular}{|c|c|c|c|c|}
\hline \multirow[b]{2}{*}{ Gene } & \multicolumn{2}{|l|}{ Primer sequence $\left(5^{\prime}-3^{\prime}\right) *$} & \multirow{2}{*}{$\begin{array}{l}\text { Fragment } \\
\text { size (bp) }\end{array}$} & \multirow[b]{2}{*}{ Gene bank accession } \\
\hline & Forward & Reverse & & \\
\hline$H 2 A F Z$ & AGGACGACTAGCCATGGACGTGTG & CCACCACCAGCAATTGTAGCCTTG & 209 & NM_174809 \\
\hline ACTG1 & GAGAAGCTCTGCTACGTCG & CCAGACAGCACCGTGTTGG & 255 & NM_001033618.1 \\
\hline GPX4 & TGTGGTGAAGCGGTATGGTC & TATTCCCACAAGGCAGCCAG & 266 & NM_174770.4 \\
\hline$N F E 2 L 2$ & GCTCAGCATGATGGACTTGGAG & GGGAATGTCTCTGCCAAAAGC & 390 & NM_001011678.2 \\
\hline ROCK 1 & ACGTGACCTAGTGCCTTGTG & CСTCAGTGTGCTTTTGTGCC & 164 & XM_002697789.5 \\
\hline ROCK 2 & СTTGGCTGCTCAACTGGAGA & TGCTCTTGGGCTTCCTTCAG & 276 & NM_174452.2 \\
\hline AGR3 & TGTCACACTCAGTTCTGGTCC & GTCATCTCCСCACССТCTTGA & 119 & NM_001191502.1 \\
\hline SMAD6 & GGAGAAATTCGCTCCAAGTGC & СССТGССТTTAAAACССАAGC & 242 & NM_001206145.1 \\
\hline TDGF1 & ATGGTGAGAGACGGGCTGCTAG & GCССTTGTCTCATACAGCTTCC & 201 & NM_001080358.1 \\
\hline SCN9A & GTTGATAACССTGTGCСТGGA & CTTCAAAAGCCAGAGCACCAC & 250 & XM_005202453.3 \\
\hline SOCS3 & GCGAGAAGATCCСTCTGGTG & CTAAAGCGGGGCATCGTACT & 167 & NM_174466.2 \\
\hline IGFBP3 & GAGTCCAAGCGTGAGACAGAA & GCGGCACTGCTTTTTCTTGTA & 150 & NM_174556.1 \\
\hline PRELP & CAGCATCGAGAAAATCAATGGGA & AGCACATCATGAGGTCCAGC & 158 & NM_174434.3 \\
\hline EPSTI1 & AAACGACAGCAACAGGAGGAA & CCTTGGAGTCGGTCCAGAAAA & 89 & XM_002691775.5 \\
\hline
\end{tabular}

*All the primers were designed with NCBI Primer-BLAST online tool of the National Centre for Biotechnology Information (http://www.ncbi.nlm. nih.gov/tools/primer-blast/).

products was confirmed by electrophoresis on a $2 \%$ agarose gel. All target genes showed efficiencies between 95 and $100 \%$ and correlation coefficients close to 1.0 .

All mRNA transcripts were quantified in duplicate. Each RT-qPCR reaction was performed in a final volume of $20 \mu \mathrm{L}$, containing $0.25 \mathrm{mM}$ of forward and reverse primers, $10 \mu \mathrm{L}$ of GoTaq RT-qPCR Master Mix (Promega) and $2 \mu \mathrm{L}$ of each cDNA sample derived from BOEC $(\approx 60 \mathrm{ng} / \mu \mathrm{L})$ using a Rotorgene 6000 Real-Time Cycler (Corbett Research, Sydney, Australia) and SYBR Green as double-stranded DNA-specific fluorescent dye.

Relative expression levels were quantified by the comparative cycle threshold $(\Delta \Delta \mathrm{CT})$ method (Schmittgen \& Livak 2008). Values were normalized using two housekeeping genes (H2AFZ and ACTG1). Fluorescence was acquired in each cycle to determine the threshold cycle during the log-linear phase of the reaction at which fluorescence increased above background for each sample. According to the comparative CT method, the $\Delta C T$ value was determined by subtracting the mean CT value of the two housekeeping genes for each sample from each gene CT value of the sample. Calculation of $\Delta \Delta \mathrm{CT}$ involved using the highest sample $\Delta \mathrm{CT}$ value (i.e. the sample with the lowest target expression) as an arbitrary constant to subtract from all other $\Delta \mathrm{CT}$ sample values. Fold changes in the relative gene expression of the target were determined using the formula $2^{-\Delta \Delta C T}$ (Livak \& Schmittgen 2001).

\section{Metabolic analysis}

\section{Glucose lactate and pyruvate consumption}

Concentrations of glucose, lactate and pyruvate in spent medium following culture of BOEC in the presence or absence of embryos were measured using fluorometric assays based on those described by Gardner \& Leese (1990), but with modifications (Guerif et al. 2013). All values were expressed as $\mathrm{mM}$ and were relative to a blank control to calculate consumption rate.

\section{Amino acid profiling}

The analysis of 18 amino acids in spent medium was performed using high-performance liquid chromatography (HPLC) as previously described (Houghton et al. 2002). All values were expressed in $\mu \mathrm{M}$ and were relativized to blank control to calculate consumption rate.

\section{Experimental design}

Experiment 1: Direct and indirect effects of the embryo on the BOEC gene expression

An in vitro co-culture system was established to allow a localized and temporal contact between BOEC and early bovine embryos. Isthmic epithelial cells obtained from a pool of three post-ovulatory stage oviducts on each day (day=replicate, four replicates) were cultured until confluence/monolayer for 6 days. Based on our previous studies (Barrera et al. 2017, García et al. 2017), where the highest proportions of two- and eight-cell embryos were observed at 31 and 52 hpi respectively, in this experiment embryos, at the two- and eight-cell stages were generated by IVF and removed from culture at 31 or $52 \mathrm{hpi}$ respectively to be cultured during $48 \mathrm{~h}$ to either generate fresh CM (four replicates) or co-cultured with BOEC (four replicates) (Fig. 2A). BOECs were cultured for 48 $\mathrm{h}$ as follows: (1) directly beneath and in direct contact with 50 embryos at the two- or eight-cell stage $\left(\mathrm{BOEC}^{+}\right)$; $(2)$ in the same well as 50 embryos at the two- or eight-cell stage but not in direct contact with the embryos $\left(\mathrm{BOEC}^{-}\right.$); (3) with $\mathrm{CM}$ from embryos at the two- or eight-cell stage (BOEC ${ }^{\mathrm{CM}}$ ) and (4) without embryos or CM (control, BOEC) (Fig. 2B). Following $48 \mathrm{~h}$ of culture, BOECs were collected from the marked area from all groups by mechanical scraping to perform RT-qPCR. The mRNA abundance of genes that had previously been shown to be affected by the presence of embryos from an in vivo study (Maillo et al. 2015: SMAD6, TDGF1, ROCK1, ROCK2, SOCS3, PRELP, AGR3, NFE2L2) and from in vitro studies (Schmaltz-Panneau et al. 2014, 2015: GPX4, SCN9A, EPSTI1, IGFBP3) were analyzed as described earlier. 
Experiment 2: Effect of early embryo on BOEC metabolism

After $48 \mathrm{~h}$ of co-culture, the media obtained from the previous experimental groups $\left(\mathrm{BOEC}^{+}, \mathrm{BOEC}^{\mathrm{CM}}, \mathrm{BOEC}\right)$ as well as the spent media obtained from embryos cultured alone (EMB) were collected to assess the metabolic changes that may result from interaction of BOEC with the embryos or with their CM, by analyzing the energy substrate and amino acid composition. As blank control, embryo/BOEC-free media was treated in the same manner as the experimental groups (Fig. 2C).

\section{Statistical analysis}

Statistical analysis was performed with the SigmaStat software package (Jandel Scientific, San Rafael, CA, USA). The Kolmogorov-Smirnov test was applied to assess data normality. Differences in embryo development were analyzed using chisquare. Differences in the relative mRNA abundance levels and metabolic results were analyzed using one-way ANOVA followed by Holm-Sidak post hoc test, when applicable, to determine the statistical differences between the experimental groups. When normality test failed Kruskal-Wallis, a nonparametric test was conducted. Values were considered significantly different when the $P$ value was lower than 0.05

\section{Results}

\section{Effect of BOEC co-culture on early embryo development in vitro}

Cleavage rates at $31 \mathrm{hpi}$ (two-cell $=774 / 1177$ ) and $52 \mathrm{hpi}$ (eight-cell $=652 / 1197$ ) were $65.5 \pm 2.5 \%$ and $54.0 \pm 7.4 \%$ respectively. After $48 \mathrm{~h}$ of co-culture, no differences were found in the percentage of twocell embryos developed to eight-cell stage between embryos co-cultured with $(57.0 \pm 1.4 \%)$ or without BOEC $(65.0 \pm 2.6 \%)$. Similarly, the percentage of 8 -cell embryos developed to 16-cell stage was not different between both groups $(51.0 \pm 4.2 \%$ vs $57.7 \pm 1.9 \%$ for embryos cultured with or without BOEC respectively).

\section{Experiment 1: Direct and indirect effects of the embryo on the BOEC gene expression}

The presence of 50 two-cell embryos, in direct contact, or their CM decreased the relative abundance of GPX4, ROCK2 and SCN9A in BOEC in comparison with the control group $(P<0.05)$. Abundance of SMAD6 was decreased in the presence of embryos, irrespective of direct contact, but was not altered following exposure to $\mathrm{CM}$. The only difference between cells cultured in direct or indirect contact with embryos was observed for NFE2L2 gene, which decreased in cells directly cultured with embryo or their CM in comparison with the culture in indirect contact or control groups. Culture of BOEC with $\mathrm{CM}$ increased expression of IGFBP3 $(P<0.05)$ compared with the control, but no difference was observed with the rest of groups (Fig. 3A). The remaining genes were unaffected by treatment $(P>0.05)$ (Fig. 3A).

Co-culture in the presence of eight-cell embryos or their CM revealed a different expression pattern of many of the analyzed genes to that observed with two-cell embryos. PRELP was decreased $(P<0.05)$ in the direct or indirect presence of eight-cell embryos or their $\mathrm{CM}$ in comparison with the control group. Also, BOEC directly exposed to eight-cell embryos or their CM exhibited decreased expression of SOCS3 and increased expression of SCN9A in comparison with BOEC cultured in indirect contact with embryos and with the control $(\mathrm{P}<0.05)$. GPX4 was only decreased in BOEC cultured directly with embryos in comparison with the other groups. Furthermore, the expression level of NFE2L2 was increased $(P<0.05)$ in cells cultured with CM compared to the control but no differences were observed with the rest of groups. Also, abundance of ROCK 1 and ROCK2 was increased $(P<0.05)$ in cells cultured with $C M$ in comparison to the control or to the direct culture with embryos, but it was similar to the indirect contact group. SMAD6 is the only gene that maintained the pattern of expression between BOEC co-cultured with either

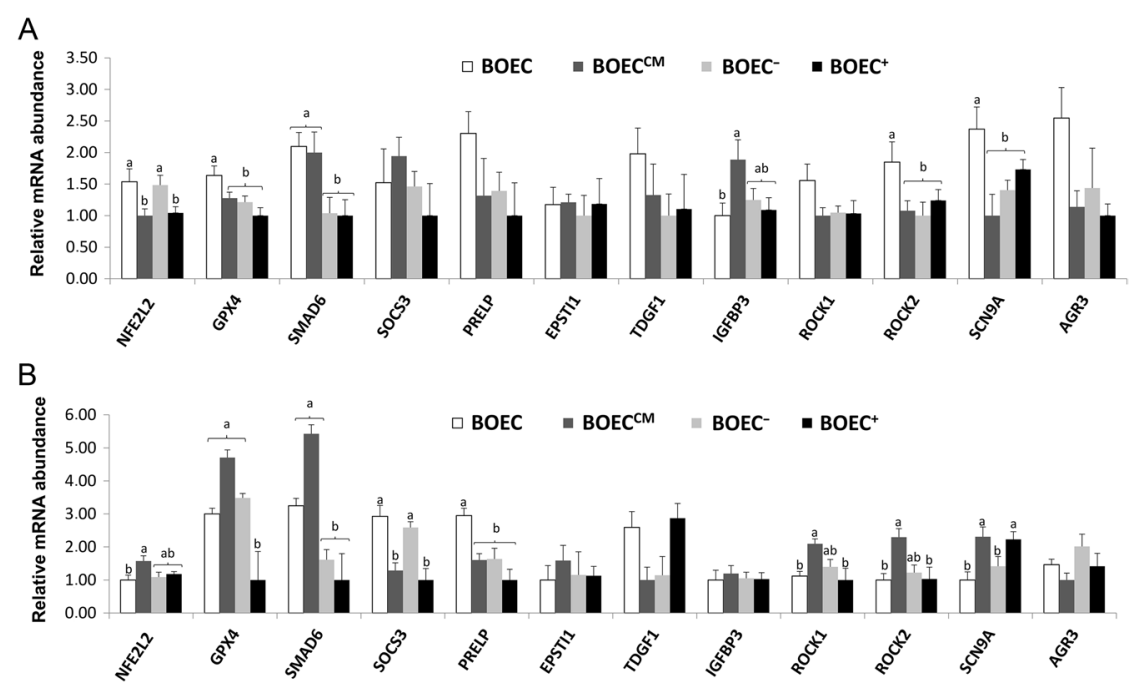

Figure 3 Relative mRNA abundance of genes assessed in BOEC cultured with two-cell (A) or eight-cell (B) stage embryos. $\mathrm{BOEC}^{+}$: BOEC directly beneath to embryos. $\mathrm{BOEC}^{-}$: $\mathrm{BOEC}$ in the same well as embryos but not in direct contact. BOEC ${ }^{\mathrm{CM}}$ : BOEC cultured with embryo CM. BOEC: cultured without embryos or CM. Bars represent the relative abundance of the transcripts analyzed and normalized to $\mathrm{H} 2 \mathrm{AFZ}$ and ACTG1 as housekeeping genes. Results are expressed as means \pm S.E.M. Different superscripts indicate significant differences $(P<0.05)$ between groups. Data were obtained from four replicates of independent BOEC samples per experimental group. 
two- or eight-cell embryos, where it decreased in BOEC cultured in direct or indirect contact with embryos in comparison with the rest of groups $(P<0.05)$ (Fig. 3B). The remaining genes did not exhibit an alteration of their expression due to treatment $(P>0.05)$ (Fig. 3B).

\section{Experiment 2: Effect of early embryo on BOEC metabolism}

\section{Glucose, lactate and pyruvate consumption}

Glucose, lactate and pyruvate consumption by BOEC was not affected by the presence of two-cell or eight-cell embryos (Fig. 4A and B). Indeed, a similar consumption of glucose and pyruvate by BOEC was observed whether they were cultured independently with or without embryos or CM. However, BOEC consumption of those substrates was higher than embryo consumption $(P<0.001$ for two-cell embryos; $P<0.005$ for eight-cell embryos). In contrast, lactate production was elevated in BOEC cultured with CM from two-cell embryos and in media from two-cell embryos cultured alone in comparison with the other groups $(P<0.001)$ (Fig. 4A). Lactate consumption was also higher in BOEC cultured alone or with eight-cell embryos and in media from eight-cell embryos cultured alone in comparison with BOEC cultured with CM $(P<0.005)$ (Fig. 4B). Regarding embryo metabolism, two-cell embryos cultured without BOEC did not reveal a consumption of energy substrates when they were compared to the blank control (data of blank media were not included in the graphs).

\section{Amino acid profiling}

The results of HPLC revealed that among the 18 amino acids analyzed, the concentration of ten was affected in BOEC co-cultured with two-cell embryos and 12 in the BOEC co-cultured with eight-cell embryos. These amino acids were significantly highly depleted in BOEC cultured alone or with embryos or with CM compared with both stage embryos cultured alone, except for alanine having the opposite pattern (Fig. 5A and B) $(P<0.005)$. Similar to alanine, serine had the same tendency of accumulation, but significant differences were observed only for eight-cell embryos in BOEC cultured alone or with embryos or CM compared with eight-cell embryos cultured alone $(P<0.005)$ (Fig. 5B). Regarding embryo metabolism, two-cell embryos cultured without BOEC did not reveal a consumption of amino acids substrates when they were compared to the blank control (data of blank media were not included in the graphs).

\section{Discussion}

We have previously reported that oviduct transcriptome changes produced by the presence of an embryo may be very local in nature (Maillo et al. 2015). The present study aimed to validate these data using an in vitro model

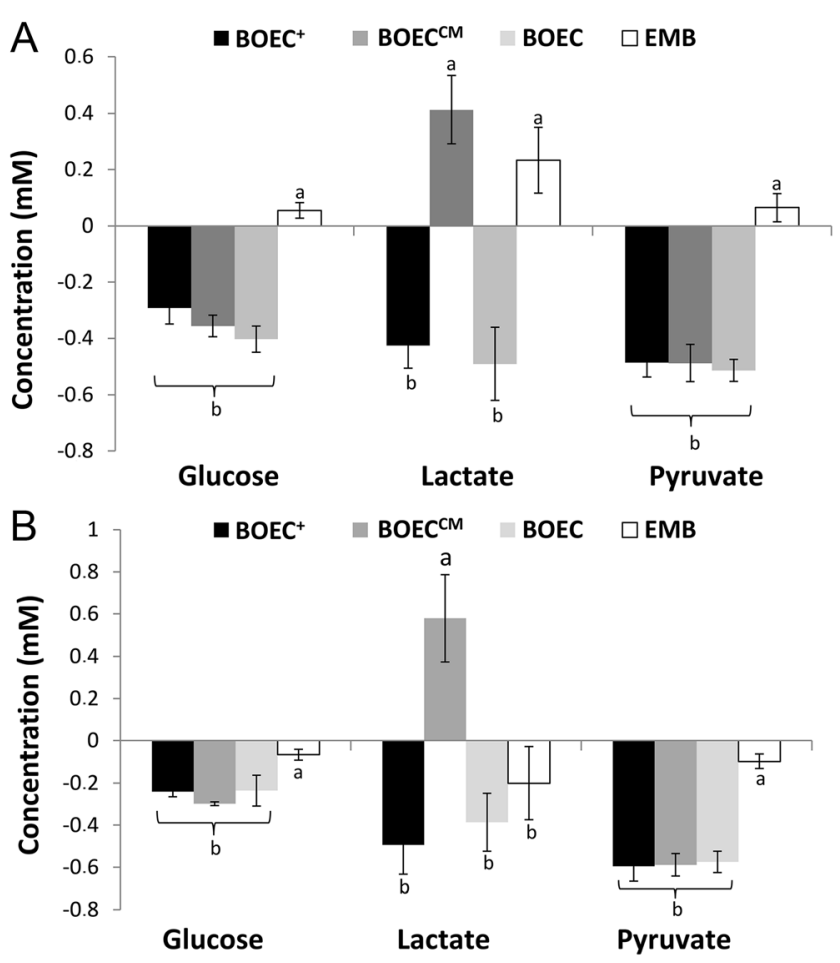

Figure 4 Energy substrate analysis (glucose, lactate and pyruvate) in BOEC cultured with two-cell (A) or eight-cell (B) stage embryos. Depletion/production data are expressed relative to a control blank media. Values are expressed as means \pm S.E.M. BOEC ${ }^{+}$, BOEC co-cultured with embryos; $\mathrm{BOEC} \mathrm{CM}^{\mathrm{M}}$, BOEC cultured with embryo $\mathrm{CM}$; BOEC, BOEC cultured neither with embryos nor with their $\mathrm{CM}$; $E M B$, embryos cultured alone. Different superscripts indicate significant differences between groups $(A, P<0.001) ;(B, P<0.005)$. All the groups included under the brackets are statistically similar between each other, but they are different to the other group(s).

which offered the double benefit of immobilizing the embryo on the surface of the BOEC monolayer during co-culture, enabling the analysis of the local interaction between BOEC and embryos. In this model, we chose to use 50 embryos as we wanted to amplify any putative signal, also this number corresponds to the number of embryos transferred in the study of Maillo et al. (2015).

The response of BOEC to two- and eight-cell embryos or their CM was evaluated at gene expression and metabolic levels. The overall transcriptional profile of a panel of candidate genes between BOEC co-cultured with two-cell embryos or with their CM was different from that observed after co-culture with eightcell embryos or their CM. In cattle, the major activation of transcription occurs during the 8- to 16-cell stage (reviewed by Graf et al. 2014). These events perhaps are accompanied by specific embryo signaling. Evidence is emerging of a dynamic mutual paracrine communication between both the embryonic and the maternal environments, through extracellular vesicles $(E V s)$, at the early stages of preimplantation embryo development (Saadeldin et al. 2015, Almiñana et al. 2017). 

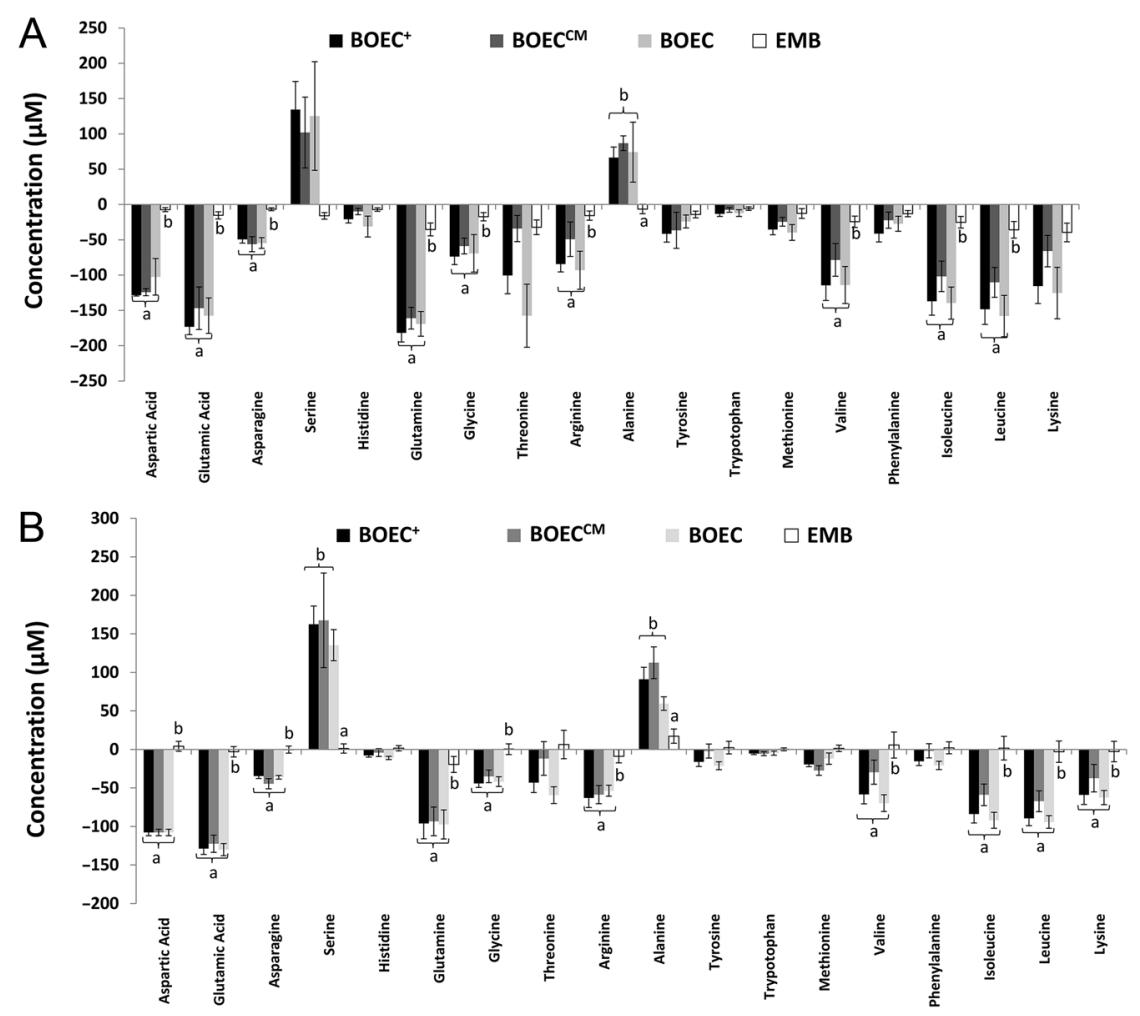

Figure 5 Amino acid metabolism in BOEC
CO-cultured with two-cell (A) or eight-cell (B)
stage embryos. Depletion/production data are
expressed relative to a control blank media.
Values are expressed as means \pm S.E.M. BOEC
BOEC co-cultured with embryos; BOEC ${ }^{C M}$,
BOEC cultured with embryo CM; BOEC,
BOEC cultured neither with embryos nor with
their CM; EMB, embryos cultured without
BOEC. Different superscripts indicate
differences between groups $(P<0.005)$. All the
groups included under the brackets are
statistically similar between each other, but
they are different to the other group(s).

For example, the secretome of in vitro-cultured human embryos contains EVs that are taken up by the maternal side (Giacomini et al. 2017). In support of the existence of stage-specific effects of the embryo on the reproductive tract, data from Passaro et al. (2018) have shown that bovine endometrial explants respond to the presence of 8-day-old blastocysts and not to earlier stages (oocytes, two-cell, Day 5 morula).

Serum has been associated with reduced blastocyst quality, although it is still used for embryo culture (e.g., 5-10\%) (reviewed by Rizos et al. 2017). We have reported that $10 \%$ FCS accelerates blastocyst development, with more blastocysts appearing at Day 6 after IVF than when it is absent and that this accelerated development was associated with poorer survival following cryopreservation (Rizos et al. 2003). However, others working in commercial IVF/ET in Brazil routinely use low concentrations (e.g., 2.5\%) of FCS and report no difference in survival following cryopreservation or conception rates after transfer (Sanches et al. 2016). Also, BOEC cultures typically require the presence of serum for normal development, cell attachment, growth and proliferation (Brunner et al. 2010). Thus, FCS was supplemented to all experimental groups.

Results indicate that BOEC mRNA abundance was affected directly by embryos or by their secretions, depending on the transcript analyzed, which indicates the complexity of the mechanisms implicated in embryo-maternal communication. The oviductal mRNA abundance of SMAD6 decreased in the presence of both two- and eight-cell embryos, consistent with our previous data indicating the relevance of SMAD6 as a component of the BMP signaling pathway (García et al. 2017).

SOCS3, PRELP and SCN9A expression was affected in BOEC cultured in direct contact with eight-cell embryos and their CM. The fact that eight-cell embryos decreased the expression of SOCS3 and PRELP, implicated in immune defense, supports the idea that embryo may avoid the maternal immune response by decreasing inflammation (Maillo et al. 2015). This agrees with data obtained from the comparison of ipsilateral oviducts from pregnant and cyclic mares, showing that the embryo modifies the expression of immune responserelated genes with marked upregulation of interferonassociated genes (Smits et al. 2016). This is also consistent with recent data indicating that BOEC stimulates embryos to produce IFNT, which then acts on immune cells to promote an anti-inflammatory response in the oviduct (Talukder et al. 2018). Expression of SCN9A was upregulated in BOEC cO-cultured with eight-cell embryos or their CM. This is consistent with the study of Schmaltz-Panneau et al. (2014) who hypothesized that there is neurotrophin signaling by the embryo at the time of blastocyst formation (Schmaltz-Panneau et al. 2014). Furthermore, SCN9A mediates the voltage-dependent sodium ion permeability of excitable cell membrane. (Chan et al. 2012). Taking this information into account, our results indicate that during its passage through the oviduct, the early embryo might affect the epithelial ion channels modulating the luminal fluid volume and composition according to its needs. 
The IGFBP3 transcript was also increased in BOEC cultured with $\mathrm{CM}$ of two-cell embryos, a finding consistent with previous reports of an increase of IGFBP3 in BOEC Co-cultured for 8 days with 20 early embryos (Schmaltz-Panneau et al. 2014). IGFBP3 belongs to a family of six binding proteins that bind insulin-like growth factor 1 and 2 (IGF-1 and -2). It was demonstrated that the bovine oviduct expresses IGFBP-3 in a region-specific manner in the isthmus epithelium. This pattern of distribution might help to create an IGF-1 gradient along the oviduct as the embryo travels through it (Pushpakumara et al. 2002).

Recently, changes in the oviduct microenvironment in its metabolite levels related to the stage of the cycle and the proximity of ovulation have been reported (Lamy et al. 2018). However, whether the embryo can elicit similar responses is largely unknown. Consequently, we sought to evaluate the effect of the early embryo on the metabolism of energy substrates and amino acids of BOEC cultured in vitro. Results indicate that BOEC metabolism was not affected by the presence of early embryos (two-cell or eight-cell stage) or by their CM. Furthermore, results indicate that BOEC metabolism is different to that of embryos, suggesting that BOEC and embryos have metabolic requirements that may be independently satisfied in vitro by the culture media. BOEC consumed glucose, lactate and pyruvate as well as amino acids, except for serine and alanine, which were produced by cells. It has previously been proposed that BOEC altered the composition of culture medium in a manner consistent with embryo development; indeed, BOECdepleted glucose concentrations while there was an accumulation of lactate and pyruvate, two key metabolites required for successful development of the early embryo indicating that BOEC might be attempting to create an environment favorable for embryo development (Edwards et al. 1997). However, it is important to note that in their experiment, Edwards et al. (1997) performed the co-culture in SOFaa media supplemented with high levels of carbohydrates, mimicking those present in TCM-199. In contrast, our study used SOFaa that was free of carbohydrates, following the composition previously described (Holm et al. 1999) which may explain the discrepancies in results.

Interestingly, embryo metabolism before EGA seems to be independent of the environment. The results indicated no consumption of energy substrate or amino acids by two- to eight-cell embryos. However, this was not the case for embryos at the 8- to 16-cell stage which displayed an active metabolism. The lack of metabolism by two- to eight-cell embryos may suggest that the embryo has sufficient endogenous energy sources, most likely fat but possibly protein, to support its early development (Sturmey et al. 2009, Leese 2015).
The amino acid analysis revealed the production of serine and alanine by BOEC independent of the presence of embryos. The release of alanine amino acid in the extracellular medium is witness of ammonium detoxification mediated by pyruvate metabolism (reviewed by de Souza et al. 2015). Furthermore, alanine is involved in the regulation of intracellular $\mathrm{pH}$ and may have a role in protecting the embryo from osmotic stress (Van Winkle 2001), and it has shown to promote bovine preimplantation development in vitro (Moore \& Bondioli 1993). Thus, BOEC could be predisposed to increase alanine concentration in the media to sustain embryo needs.

In conclusion, using an in vitro approach allowing a local and temporal interaction between the embryo and oviduct epithelial cells, this study confirms that the early embryo affects the gene expression of BOEC. The effect was embryo stage specific and resulted from a direct contact with BOEC or from embryo secretions released into the media. Under our experimental conditions the early embryo did not affect BOEC metabolism indicating that during its short passage through the oviduct, it might elicit changes at signaling level necessary for its development without inducing metabolic changes.

\section{Declaration of interest}

The authors declare that there is no conflict of interest that could be perceived as prejudicing the impartiality of the research reported.

\section{Funding}

This work was funded by the Spanish Ministry of Economy and Competitiveness (AGL2015-70140-R to D Rizos and AGL2015-66145-R to A Gutierrez-Adan). M Hamdi was supported by a fellowship from the Spanish Ministry of Economy and Competitiveness (BES-2013-066767). The authors are also funded by the European Union H2020 Marie Sklodowska-Curie (MSCA) Innovative Training Network (ITN) project 'Biology and Technology of Reproductive Health REP-BIOTECH-675526'. The authors are members of the COST Action 16119. In vitro 3D total cell guidance and fitness (Cellfit).

\section{Acknowledgments}

The authors would like to thank Almansa Ordóñez A and Barroso Sáenz A for their help. Special thanks are extended to the abattoirs (Transformación Ganadera De Leganés SA; Matadero Madrid Norte, San Agustín de Guadalix; and Cárnica Colmenar SC, in Madrid, Spain) for providing access to the biological material (ovaries) and to the Spanish Association of Breeders of Selected Cattle of the Asturian Valley Breed (ASEAVA) for providing the semen. 


\section{References}

Almiñana C, Heath PR, Wilkinson S, Sanchez-Osorio J, Cuello C, Parrilla I, Gil MA, Vazquez JL, Vazquez JM, Roca J et al. 2012 Early developing pig embryos mediate their own environment in the maternal tract. PLOS ONE 7 e33625. (https://doi.org/10.1371/journal.pone.0033625)

Almiñana C, Corbin E, Tsikis G, Alcântara-Neto AS, Labas V, Reynaud K, Galio L, Uzbekov R, Garanina AS, Druart X et al. 2017 Oviduct extracellular vesicles protein content and their role during oviductembryo cross-talk. Reproduction 154 153-168. (https://doi.org/10.1530/ REP-17-0054)

Barrera AD, García EV, Hamdi M, Sánchez-Calabuig MJ, LópezCardona ÁP, Balvís NF, Rizos D \& Gutiérrez-Adán A 2017 Embryo culture in presence of oviductal fluid induces DNA methylation changes in bovine blastocysts. Reproduction 154 1-12. (https://doi.org/10.1530/ REP-16-0651)

Bermejo-Alvarez P, Rizos D, Rath D, Lonergan P \& Gutierrez-Adan A 2008 Epigenetic differences between male and female bovine blastocysts produced in vitro. Physiological Genomics 32 264-272. (https://doi. org/10.1152/physiolgenomics.00234.2007)

Brunner D, Frank J, Appl H, Schöffl H, Pfaller W \& Gstraunthaler G 2010 Serum-free cell culture: the serum-free media interactive online database. ALTEX 27 53-62. (https://doi.org/10.14573/ altex.2010.1.53)

Chan HC, Chen H, Ruan Y \& Sun T 2012 Physiology and pathophysiology of the epithelial barrier of the female reproductive tract: role of ion channels. Advances in Experimental Medicine and Biology 763 193-217.

Chang HS, Cheng WTK, Wu HK \& Choo KB 2000 Identification of genes expressed in the epithelium of porcine oviduct containing early embryos at various stages of development. Molecular Reproduction and Development $\mathbf{5 6}$ 331-335. (https://doi.org/10.1002/10982795(200007)56:3<331::AID-MRD1>3.0.CO;2-K)

Chen S, Palma-Vera SE, Langhammer M, Galuska SP, Braun BC, Krause E, Lucas-Hahn A \& Schoen J 2017 An air-liquid interphase approach for modeling the early embryo-maternal contact zone. Scientific Reports 7 42298. (https://doi.org/10.1038/srep42298)

Chen S, Palma-Vera SE, Kempisty B, Rucinski M, Vernunft A \& Schoen J 2018 In vitro mimicking of estrous cycle stages: dissecting the impact of estradiol and progesterone on oviduct epithelium. Endocrinology 159 3421-3432. (https://doi.org/10.1210/en.2018-00567)

de Souza DK, Salles LP \& Rosa e Silva AA 2015 Aspects of energetic substrate metabolism of in vitro and in vivo bovine embryos. Brazilian Journal of Medical and Biological Research 48 191-197. (https://doi. org/10.1590/1414-431X20143744)

Edwards LJ, Batt PA, Gandolfi F \& Gardner DK 1997 Modifications made to culture medium by bovine oviduct epithelial cells: changes to carbohydrates stimulate bovine embryo development. Molecular Reproduction and Development 46 146-154. (https://doi.org/10.1002/ (SICI)1098-2795(199702)46:2<146::AID-MRD5>3.0.CO;2-Q)

Enright BP, Lonergan P, Dinnyes A, Fair T, Ward FA, Yang X \& Boland MP 2000 Culture of in vitro produced bovine zygotes in vitro vs in vivo: implications for early embryo development and quality. Theriogenology 54 659-673. (https://doi.org/10.1016/S0093-691X(00)00381-2)

Ferraz MAMM, Rho HS, Hemerich D, Henning HHW, van Tol HTA, Hölker M, Besenfelder U, Mokry M, Vos PLAM, Stout TAE et al. 2018 An oviduct-on-a-chip provides an enhanced in vitro environment for zygote genome reprogramming. Nature Communications 9 4934. (https://doi. org/10.1038/s41467-018-07119-8)

García EV, Hamdi M, Barrera AD, Sánchez-Calabuig MJ, GutiérrezAdán A \& Rizos D 2017 Bovine embryo-oviduct interaction in vitro reveals an early cross talk mediated by BMP signaling. Reproduction 153 631-643. (https://doi.org/10.1530/REP-16-0654)

Gardner DK \& Leese HJ 1990 Concentrations of nutrients in mouse oviduct fluid and their effects on embryo development and metabolism in vitro. Journal of Reproduction and Fertility 88 361-368. (https://doi. org/10.1530/jrf.0.0880361)

Giacomini E, Vago R, Sanchez AM, Podini P, Zarovni N, Murdica V, Rizzo R, Bortolotti D, Candiani M \& Viganò P 2017 Secretome of in vitro cultured human embryos contains extracellular vesicles that are uptaken by the maternal side. Scientific Reports 7 5210. (https://doi. org/10.1038/s41598-017-05549-w)
Graf A, Krebs S, Heininen-Brown M, Zakhartchenko V, Blum H \& Wolf E 2014 Genome activation in bovine embryos: review of the literature and new insights from RNA sequencing experiments. Animal Reproduction Science 149 46-58. (https://doi.org/10.1016/j.anireprosci.2014.05.016)

Guerif F, McKeegan P, Leese HJ \& Sturmey RG 2013 A simple approach for COnsumption and RElease (CORE) analysis of metabolic activity in single mammalian embryos. PLOS ONE 8 e67834. (https://doi. org/10.1371/journal.pone.0067834)

Hackett AJ, Durnford R, Mapletoft RJ \& Marcus GJ 1993 Location and status of embryos in the genital tract of superovulated cows 4 to 6 days after insemination. Theriogenology 40 1147-1153. (https://doi. org/10.1016/0093-691X(93)90285-D)

Holm P, Booth PJ, Schmidt MH, Greve T \& Callesen H 1999 High bovine blastocyst development in a static in vitro production system using SOFaa medium supplemented with sodium citrate and myo-inositol with or without serum-proteins. Theriogenology 52 683-700. (https:// doi.org/10.1016/S0093-691X(99)00162-4)

Houghton FD, Hawkhead JA, Humpherson PG, Hogg JE, Balen AH, Rutherford AJ \& Leese HJ 2002 Non-invasive amino acid turnover predicts human embryo developmental capacity. Human Reproduction 17 999-1005. (https://doi.org/10.1093/humrep/17.4.999)

Ireland JJ, Murphee RL \& Coulson PB 1980 Accuracy of predicting stages of bovine estrous cycle by gross appearance of the corpus luteum. Journal of Dairy Science 63 155-160. (https://doi.org/10.3168/jds. S0022-0302(80)82901-8)

Lamy J, Gatien J, Dubuisson F, Nadal-Desbarats L, Salvetti P, Mermillod P \& Saint-Dizier M 2018 Metabolomic profiling of bovine oviductal fluid across the oestrous cycle using proton nuclear magnetic resonance spectroscopy. Reproduction, Fertility, and Development 30 1021-1028. (https://doi.org/10.1071/RD17389)

Lazzari G, Wrenzycki C, Herrmann D, Duchi R, Kruip T, Niemann H \& Galli C 2002 Cellular and molecular deviations in bovine in vitroproduced embryos are related to the large offspring syndrome. Biology of Reproduction 67 767-775. (https://doi.org/10.1095/ biolreprod.102.004481)

Lee KF, Yao YQ, Kwok KL, Xu JS \& Yeung WSB 2002 Early developing embryos affect the gene expression patterns in the mouse oviduct. Biochemical and Biophysical Research Communications 292 564-570. (https://doi.org/10.1006/bbrc.2002.6676)

Leese HJ 2015 History of oocyte and embryo metabolism. Reproduction, Fertility, and Development 27 567-571. (https://doi.org/10.1071/ RD14278)

Livak KJ \& Schmittgen TD 2001 Analysis of relative gene expression data using real-time quantitative PCR and the $2-\Delta \Delta C T$ method. Methods 25 402-408. (https://doi.org/10.1006/meth.2001.1262)

Lonergan P, Khatir H, Piumi F, Rieger D, Humblot P \& Boland MP 1999 Effect of time interval from insemination to first cleavage on the developmental characteristics, sex ratio and pregnancy rate after transfer of bovine embryos. Journal of Reproduction and Fertility 117 159-167. (https://doi.org/10.1530/jrf.0.1170159)

Lonergan P, Rizos D, Gutiérrez-Adán A, Fair T \& Boland MP 2003 Effect of culture environment on embryo quality and gene expression experience from animal studies. Reproductive Biomedicine Online 7 657-663. (https://doi.org/10.1016/S1472-6483(10)62088-3)

Lopera-Vásquez R, Hamdi M, Fernandez-Fuertes B, Maillo V, BeltránBreña P, Calle A, Redruello A, López-Martín S, Gutierrez-Adán A, Yañez-Mó M et al. 2016 Extracellular vesicles from BOEC in in vitro embryo development and quality. PLoS ONE 11 e0148083. (https://doi. org/10.1371/journal.pone.0148083)

Maillo V, Gaora PÓ, Forde N, Besenfelder U, Havlicek V, Burns GW, Spencer TE, Gutierrez-Adan A, Lonergan P \& Rizos D 2015 Oviduct-embryo interactions in cattle: two-way traffic or a one-way street? Biology of Reproduction 92 144. (https://doi.org/10.1095/ biolreprod.115.127969)

Maillo V, Lopera-Vasquez R, Hamdi M, Gutierrez-Adan A, Lonergan P \& Rizos D 2016 Maternal-embryo interaction in the bovine oviduct: evidence from in vivo and in vitro studies. Theriogenology 86 443-450. (https://doi.org/10.1016/j.theriogenology.2016.04.060)

Memili E \& First NL 2000 Zygotic and embryonic gene expression in cow: a review of timing and mechanisms of early gene expression as compared with other species. Zygote 8 87-96. (https://doi.org/10.1017/ S0967199400000861) 
Moore K \& Bondioli KR 1993 Glycine and alanine supplementation of culture medium enhances development of in vitro matured and fertilized cattle embryos. Biology of Reproduction 48 833-840. (https://doi. org/10.1095/biolreprod48.4.833)

Passaro C, Tutt D, Mathew DJ, Sanchez JM, Browne JA, Boe-Hansen GB, Fair T \& Lonergan P 2018 Blastocyst-induced changes in the bovine endometrial transcriptome. Reproduction 156 219-229. (https://doi. org/10.1530/REP-18-0188)

Pushpakumara PG, Robinson RS, Demmers KJ, Mann GE, Sinclair KD, Webb R \& Wathes DC 2002 Expression of the insulin-like growth factor (IGF) system in the bovine oviduct at oestrus and during early pregnancy. Reproduction 123 859-868. (https://doi.org/10.1530/rep.0.1230859)

Rizos D, Ward F, Duffy P, Boland MP \& Lonergan P 2002 Consequences of bovine oocyte maturation, fertilization or early embryo development in vitro versus in vivo: implications for blastocyst yield and blastocyst quality. Molecular Reproduction and Development 61 234-248. (https:// doi.org/10.1002/mrd.1153)

Rizos D, Gutiérrez-Adán A, Pérez-Garnelo S, de la Fuente J, Boland MP \& Lonergan P 2003 Bovine embryo culture in the presence or absence of serum: implications for blastocyst development, cryotolerance and messenger RNA expression. Biology of Reproduction 68 236-243. (https://doi.org/10.1095/biolreprod.102.007799)

Rizos D, Maillo V, Sánchez-Calabuig MJ \& Lonergan P 2017 The consequences of maternal-embryonic cross talk during the periconception period on subsequent embryonic development. Advances in Experimental Medicine and Biology 1014 69-86. (https:// doi.org/10.1007/978-3-319-62414-3_4)

Saadeldin IM, Oh HJ \& Lee BC 2015 Embryonic-maternal cross-talk via exosomes: potential implications. Stem Cells and Cloning: Advances and Applications 8 103-107. (https://doi.org/10.2147/SCCAA.S84991)

Sanches BV, Lunardelli PA, Tannura JH, Cardoso BL, Pereira MHC, Gaitkoski D, Basso AC, Arnold DR \& Seneda MM 2016 A new direct transfer protocol for cryopreserved IVF embryos. Theriogenology 85 1147-1151. (https://doi.org/10.1016/j.theriogenology.2015.11.029)

Schmaltz-Panneau B, Cordova A, Dhorne-Pollet S, Hennequet-Antier C, Uzbekova S, Martinot E, Doret S, Martin P, Mermillod P \& Locatelli Y
2014 Early bovine embryos regulate oviduct epithelial cell gene expression during in vitro co-culture. Animal Reproduction Science 149 103-116. (https://doi.org/10.1016/j.anireprosci.2014.06.022)

Schmaltz-Panneau B, Locatelli Y, Uzbekova S, Perreau C \& Mermillod P 2015 Bovine oviduct epithelial cells dedifferentiate partly in culture, while maintaining their ability to improve early embryo development rate and quality. Reproduction in Domestic Animals 50 719-729. (https://doi.org/10.1111/rda.12556)

Schmittgen TD \& Livak KJ 2008 Analyzing real-time PCR data by the comparative C(T) method. Nature Protocols 3 1101-1108. (https://doi. org/10.1038/nprot.2008.73)

Smits K, De Coninck DI, Van Nieuwerburgh F, Govaere J, Van Poucke M, Peelman L, Deforce D \& Van Soom A 2016 The equine embryo influences immune-related gene expression in the oviduct. Biology of Reproduction 94 36. (https://doi.org/10.1095/biolreprod.115.136432)

Sturmey RG, Reis A, Leese HJ \& McEvoy TG 2009 Role of fatty acids in energy provision during oocyte maturation and early embryo development. Reproduction in Domestic Animals 44 (Supplement 3) 50-58. (https://doi.org/10.1111/j.1439-0531.2009.01402.x)

Talukder AK, Rashid MB, Yousef MS, Kusama K, Shimizu T, Shimada M, Suarez SS, Imakawa K \& Miyamoto A 2018 Oviduct epithelium induces interferon-tau in bovine day-4 embryos, which generates an anti-inflammatory response in immune cells. Scientific Reports 87850. (https://doi.org/10.1038/s41598-018-26224-8)

Van Winkle LJ 2001 Amino acid transport regulation and early embryo development. Biology of Reproduction 64 1-12. (https://doi.org/10.1095/ biolreprod64.1.1)

Received 1 November 2018

First decision 14 January 2019

Revised manuscript received 15 April 2019

Accepted 25 April 2019 